\title{
Simulation Based Approach for Improving Outpatient Clinic Operations
}

\author{
MUHAMMAD AHMED KALWAR*, SONIA IRSHAD MARI*, MUHAMMAD SAAD MEMON*, \\ ANWARUDDIN TANWARI*, AND ALI ARSALAN SIDDIQUI*
}

RECEIVED ON 25.10.2018, ACCEPTED ON 19.02.2019

\begin{abstract}
The aim of this study is to suggest the optimum number and schedule of doctors at the OPD (Out-Patient Department) of Gastrology of a hospital in Pakistan. In order to achieve this aim, the discrete event simulation model is developed to minimize waiting time of patients. Data is collected for one week from the OPD; Data collection variables are arrival and service rate of patients, their salaries/income, patient's OPD fee, doctor's charges/patient, service time of patients at each of service channel i.e. reception, triage and doctors' cabin. Stop watch is used for recording the service time of patients. Input analyzer is used to reveal the distribution of the data. Rockwell arena software version $\mathbf{1 4 . 5}$ is used to model and simulate the queuing system of the outpatient department. Scenario analysis is conducted in four scenarios; in each of the scenario doctors were assumed to be seated for one additional hour. During the period of data collection, it is observed that most of the patients are coming with an appointment of doctors therefore, it is not justified to suggest the hiring of new doctor; especially when patients are coming for the particular doctor; therefore, already available doctors are suggested to be seated longer in the OPD; that is the way to serve the maximum number of patients in the virtual queue of patients that has been kept waiting for having an appointment and for their turn to see the doctor.
\end{abstract}

Key Words: Optimization, Simulation, Outpatient Department.

\section{INTRODUCTION}

$\mathrm{P}$ rovision of the good medical care has always been expected from the healthcare providers so that the population can be served effectively and efficiently. Healthcare service improvement is one of the important and urgent issue for Pakistan [1]. One of the essential role of healthcare systems is the improvement of health of the citizens of country [2]. It is essential for the people to have good health for the development and improvement of economic state of the country. In the comparison of service deliveries, healthcare care delivery is a kind of delivery in which the customer is more involved in the process of consumption. The patient can be harmed by the provision of bad service delivery and may lead to loss of life. In this regard, satisfaction of patients is necessary to be investigated for the sake of improvement in healthcare delivery system [3]. The side of patient satisfaction has been targeted attentively in the health care recently [4]. Patients' satisfaction is more important

Authors E-Mail: (12in10@student.muet.edu.pk, sonia.irshad@faculty.muet.edu.pk, saad.memon@faculty.muet.edu.pk, anwaruddin.tanwari@faculty.muet.edu.pk, muetanian05in04@hotmail.com)

* Department of Industrical Engineering \& Management, Mehran University of Engineering \& Technology, Jamshoro, Pakistan. 
to produce retaining customers/patients [5]. Patient satisfaction and the service quality are in a close association, good service delivery yields the retaining customers [6]. According to Suryadana [6], service quality is the difference between actual and perceived service delivery quality by the customer.

Outpatient and Emergency Departments are the most visited departments by the patients and they are also the initial contact of patients with the hospital's staff [7]. Literature indicates that in the past decade of developing counties, emergency departments are stressed on congestion and its influence on service time; furthermore, hospitals were paid attention in terms of their ability to meet the emergency needs [8]. Because of the lacking on the side of control over the customer services, the capacity planning can be complicated by service demands in the particular department. Research shows that Pakistan is also facing shortage of doctors which may be the reason of long waiting lines [9]. Nowadays, Congestion of patients in OPDs, ICUs (Intensive Care Unit), emergency departments and waiting areas is the big problem. Because of the congestion, planned queuing system do not work effectively. In daily life, queue is basically the common occurrence [10] e.g. at Hospitals, superstores, petrol pumps and CNG (Compressed Natural Gas) filling stations. When the available resources are less than entities then the queue is formed. The term delay is defined as the difference in demand of service and the associated available capacity of meeting the demand [11]. Waiting cost is associated with queues, when the patients wait in the system for getting service [12]. Waiting for long the queue often has negative influence on the satisfaction of the patient [13]. Because of the long waiting lines doctors are put to stress and due to the congestion they try to get the patients free without any deep examination, which yields customers dissatisfaction [2,1314]. Dissatisfaction incurs cost to the organizations i.e. cost of customer dissatisfaction.
In chain of health care services, hospitals are considered as one of the most important links which have impact on lives of the people. Hospitals have major influence on the prevention of diseases, early diagnosis of the diseases, management and treatment of patients [8]. The major area of focus for the hospitals is the occupancy and discharge of patients; so that the executive capacity of the system can be managed. A number of research studies are available on the subject of reforms in healthcare but an explicit frame work is required in which the performance can be judged and quantified against the performance management system [15]. Operation research and the management sciences are the subjects by the help of which managers can plan and manage the resources effectively [16].Queuing theory is the tool of operations research which is widely used for simplifying the problems of waiting lines. Mathematical approach such as queuing theory is only possible to be used when the queuing system already exists, then after the collection of data and calculation of performance measures the optimum queuing can be suggested. In contrast to the mathematical approach, simulation is more preferable. Most of the decisions are made on the results of simulation. It has been considered as more effective and more precise as compared to the mathematical model based calculations; because, in complex scenarios assumptions can be changed and behavior of the model can be observed in simulative analysis [8].

This study is aimed to suggest the optimum number/ schedule of doctors at the OPD of Gastrologyat hospital of Karachi, Pakistan.

\section{LITERATURE REVIEW}

Several studies have been conducted to improve the hospital performance. Most of the studies focus on simulation optimization methods to reduce waiting time. Agyei et. al. [10] developed discrete event simulation 
model of radiology and oncology departments to minimize the patients waiting time. Dawei et. al. [17] developed multi-objective optimization model to minimize patient's system time. Rockwell Arena simulation platform is also used to improve the healthcare performance[18-19,21]. Kittipittayakorn et. al. [18] developed healthcare simulation model and suggested optimal allocation of resource to maximize the equipment utilization. Lade et. al. [19] developed emergency services model in ARIS and Arena software. This software was used to test two assumed scenarios for the reduction of waiting time, implementing the improvement of doctor's efficiency and the quick pass process for those patients who were suffering from the minor illness. This all was done so that the bottlenecks in the system could be rectified and the resources could be allocated optimally at different stages of service. Nuñez-Perez et. al. [20] suggested optimal number of beds in emergency departments. Rockwell Arena software was used for simulation and analysis. They indicated that 179 beds should be there instead of 81. Furthermore, the patients having high degree of illness were given the priority. Table 1 summarize the literature.

In this study not only waiting time of patients was focused but the increased percentage of served patients was computed along with the service cost, revenue and the profit so that the operational managers have enough information to improve the queuing system at the OPD.

\section{RESEARCH METHODOLOGY}

\subsection{Data Collection}

OPD of Gastrology was selected for the data collection. Duration for data collection activity was 7 days. Data collection variables included arrival rate, service rate, service time taken by each resource (Doctor, Nurse, and Receptionist) per patient, income of doctor per patient, fee paid by the patient for getting served by the doctor.

\subsubsection{Arrival of Patients}

The arrival distribution of patients was not known, the inter arrival time of patients changed independently; therefore, the arrival time of patients was got down on the paper at the study area. The arrival time of patients was necessary to be noted in order to reveal the distribution that patients' arrival followed.

\subsubsection{Patients' Service Time}

The time taken by the doctor to serve the patient is called as service time. Since, resources at the OPD were receptionist $=1$, nurse $=2$, doctors $=6$; so the service time of each resource was noted with the help of stop watch.

\subsubsection{Capacity of the OPD}

Capacity of the OPD was calculated by adding up the resources available at the facility. There was one receptionist, two nurses and six doctors. Collectively, there were nine resources.

TABLE 1. SUMMARY OF LITERATURE

\begin{tabular}{|c|c|c|c|c|c|c|}
\hline \multirow{2}{*}{ Literature } & \multicolumn{2}{|c|}{ Methodology } & \multirow{2}{*}{ Decision Variable(s) } & \multicolumn{3}{c|}{ Objective Function } \\
\cline { 2 - 3 } & Simulation & Analytical & & Waiting Time & Service Cost & Waiting Cost \\
\hline Agyei et. al. [10] & $\mathrm{X}$ & & Resource allocation & $\mathrm{X}$ & & \\
\hline Dawei et.al. [17] & & $\mathrm{X}$ & Resource allocation & $\mathrm{X}$ & & $\mathrm{X}$ \\
\hline Kittipittayakorn et. al. [18] & & & Resource allocation & $\mathrm{X}$ & & \\
\hline Lade Ishan et.al. [19] & $\mathrm{X}$ & & Resource allocation & $\mathrm{X}$ & & \\
\hline Nuñez-Perez et.al. [20] & $\mathrm{X}$ & & Hospital bed requirements & $\mathrm{X}$ & & \\
\hline Mwafak Shakoor et.al. [21] & $\mathrm{X}$ & & Resource allocation & & & \\
\hline This Research & $\mathrm{X}$ & & Doctor and triage scheduling & $\mathrm{X}$ & $\mathrm{X}$ & $\mathrm{X}$ \\
\hline
\end{tabular}

Mehran University Research Journal of Engineering \& Technology, Volume 39, No. 1, January, 2020 [p-ISSN: 0254-7821, e-ISSN: 2413-7219] 


\subsubsection{Queue Discipline}

There are various queue disciplines e.g. FCFS (First Come First Served), FCLS (First Come Last Served), LCFS (Last Come First Served), SIRO (Service in Random Order); but in this study, FCFS queue discipline was preferred.

\subsubsection{Input Analysis}

Analysis of the input variables i.e. arrival and service times was conducted into input analyzer of the Rockwell arena software version 14.5. After the input analysis, the arrival and service distributions of the data were revealed which were put into the several processes in the simulation model.

\subsection{DEVELOPMENT OF SIMULATION MODEL}

After the input analysis of the collected data, the queuing system of the OPD was modelled from the reception to the service by the doctors (Figs. 10-11).

\subsubsection{Cost Analysis}

Cost analysis was conducted in which, cost of hospital, earning of doctors, waiting cost of patients, total revenue and hospital's profit were calculated for each scenario.

$\mathrm{N}=$ Number of Working Hours of the OPD

$\mathrm{n}=$ Number of Patients

Total Amount charged per patient by the hospital = Rs.300/-

Rs.300/- was the amount which was supposed to be paid by the patient at the OPD in order to see the doctor.

Service cost of Doctors/patient $=$ Rs.70/-

Rs.70 was amount which was supposed to be paid to the doctor for consulting one patient.
Receptionist Service Cost: Monthly salary i.e. Rs. 12000 of receptionist was collected from the OPD and the service cost per minute was calculated: because it was the part of analysis to calculate the cost of receptionist per patient and the time taken by receptionist to serve the patients was in minutes.

Nurse Service Cost: Similarly, to the receptionist's cost, nurse's cost was calculated in the same way. The salary of the nurse (Rs.10000/-) was collected from the OPD. Since the customer had to pass from the triage therefore the cost of nurse per minute was necessary to be calculated.

Total Service Cost: This cost was calculated by summing up the doctors cost, receptionist's cost, nurse's service cost and on the multiplication of whole sum with the number of patients coming at the OPD, total service cost was taken out.

Patient's Waiting Cost: Salaries/monthly income of patients was collectedfrom the patients. This was the cost of time that they had to wait in the queues (reception, triage, doctor).

Patients' Total System Cost: This cost was calculated by multiplying the time that patients spent at the OPD by the income that could have been generated if he/she would be at his/her work.

Total Revenue: Revenue was calculated by multiplying the number of arriving patients with the amount of Rs. 300/- (The amount charged by the OPD per patients).

Total Profit: Profit was calculated by subtracting the total incurred cost from the total generated revenue.

Receptionist's service cost $/$ minute $=$ salary of month/ $(30 \times \mathrm{N} \times 60)$

Nurse's service cost $/$ minute = salary of month/ $(30 \times \mathrm{N} \times 60)$

Each patient's service cost $=70+$ receptionist's service time (min.) x receptionist's service cost/patient + Nurse's service time (min.) x Nurse's service cost/patient

Mehran University Research Journal of Engineering \& Technology, Volume 39, No. 1, January, 2020 [p-ISSN: 0254-7821, e-ISSN: 2413-7219] 
Total service cost/patient $=\mathrm{n} \times$ Each patients' service cost

Patient's waiting cost $/$ minute $=$ Monthly salary of patient $/$ $(30 \times 8 \times 60)$

Patient's total system cost $=$ Total System time $\mathrm{x}$ Patient's waiting cost/minute

Total revenue $=\mathrm{n} \times$ amount charged by the hospital/ patient

Hospital's profit $=$ Total revenue $-($ total service $\cos t)$

\section{ASSUMPTIONS OF THE RESEARCH}

Assumptions play a vital role in bridging the real world to mathematical world. Mathematical models are good only because of the good assumptions. In the case of incorrect assumptions or not explicitly described; results would be difficult to assess and misleading as well [22]. Following assumptions were made during the development of the model:

All of the six doctors were there at the OPD for five hours.
- Breaks e.g. tea and prayer were not kept into the consideration.

- Occasional non-availability of resources was not considered in this research.

- $\quad$ Only the waiting cost of patient was included in the study; waiting cost of those people who came along was not considered.

- Until the patient was in the OPD, his/her waiting cost was counted.

- $\quad$ Service cost was calculated by summing up the salaries of resources.

\section{RESULTS}

\subsection{Input Analysis of the Collected Data}

\subsubsection{Arrival Distribution of Patients at the OPD}

As discussed earlier, input analysis was conducted in the input analyzer of Rockwell arena. Arrival distribution of patients was indicated to be poison distribution (POIS (19.9)) with the square error $=0.002798$ which can be seen in Fig. 1.

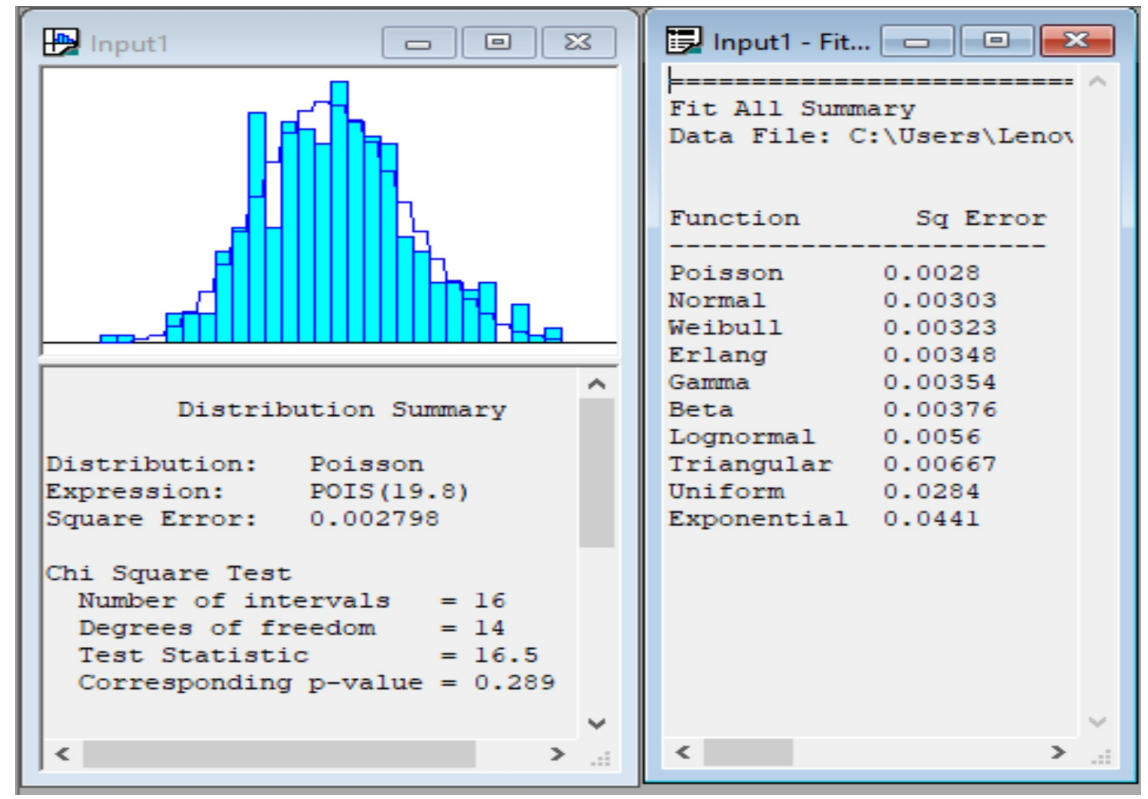

FIG. 1. DISTRIBUTION OF ARRIVING PATIENTS 


\subsubsection{Patients' Service Distribution at Reception}

Patients' service distribution at reception counter came out to be triangular distribution (TRIA $(1.8,3.15,3.18)$ ) with the square error $=0.002798$ which can be seen in Fig. 2.

\subsubsection{Patients' Service Distribution by Nurse}

Distribution of service of patients by nurse was taken out to be normal distribution (NORM $(2.14,0.442))$ with the square error $=0.002798$ which can be seen in Fig. 3.

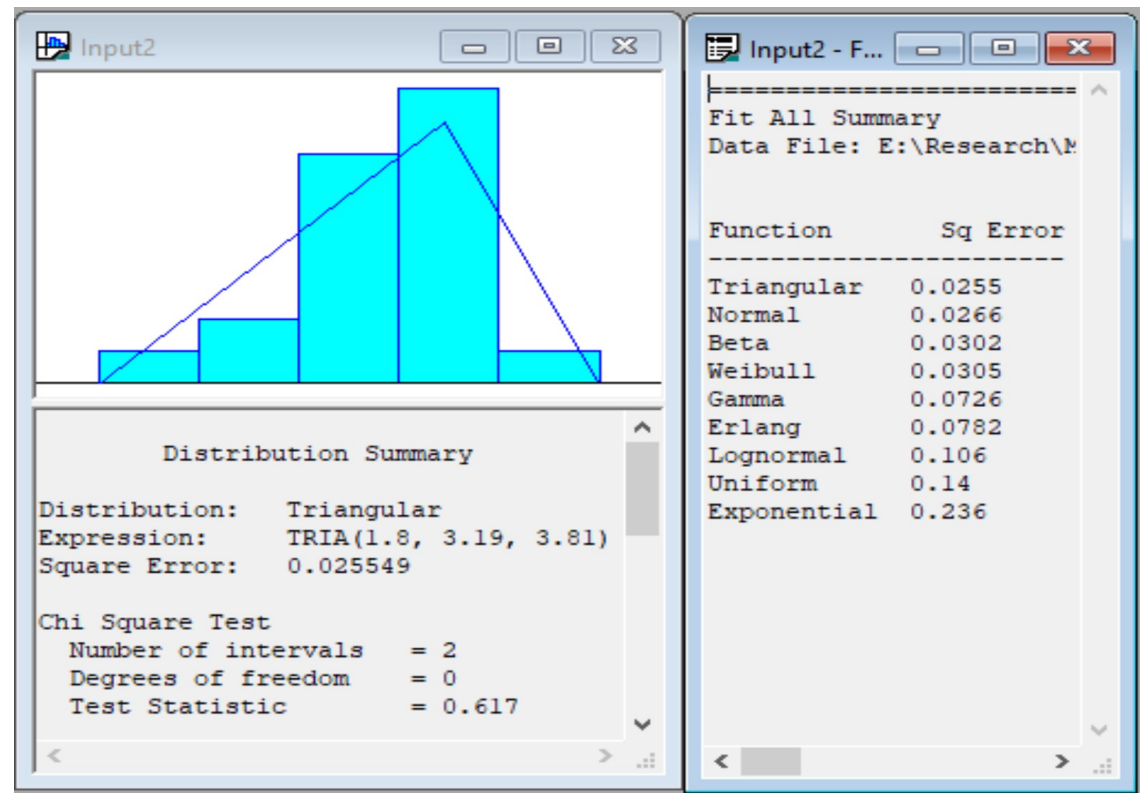

FIG. 2. SERVICE DISTRIBUTION OF PATIENTS BY THE RECEPTIONIST

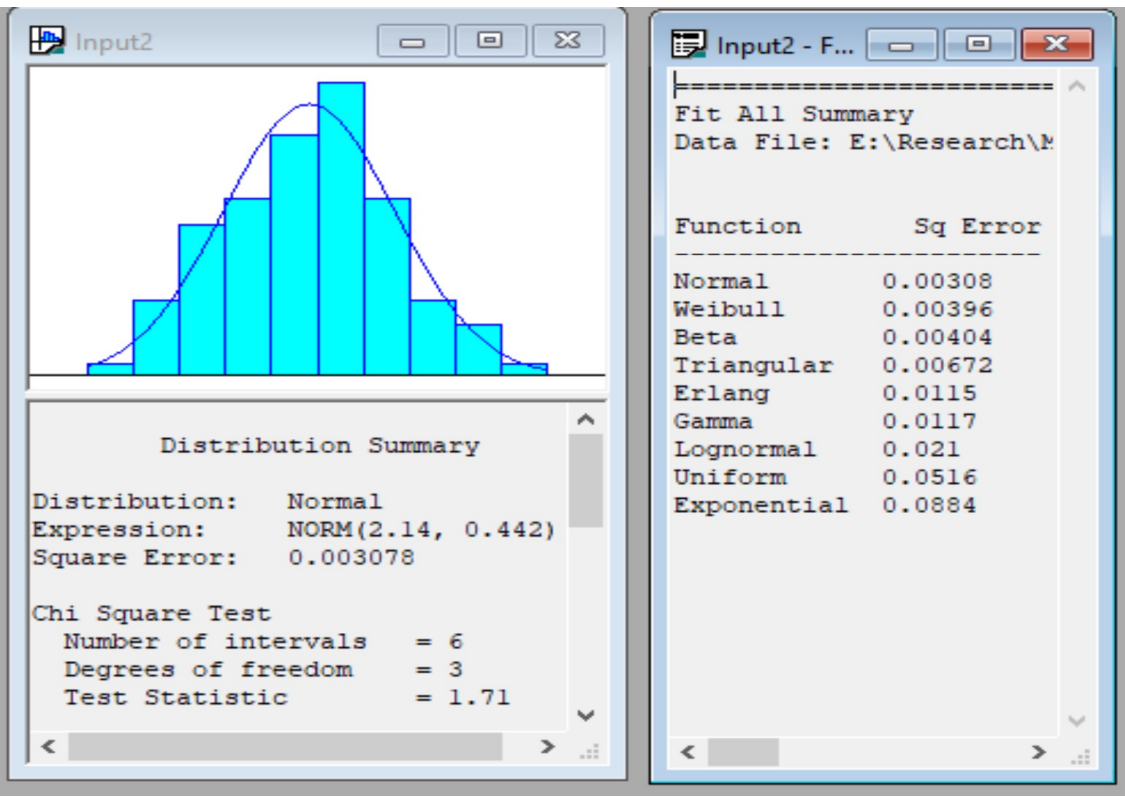

FIG. 3. DISTRIBUTION OF SERVED PATIENTS BY NURSE 


\subsubsection{Patients' Service Distribution by Doctor1}

Distribution of patients' service by doctor1 was taken out to be beta distribution $(1+4 \mathrm{x}$ beta $(1.57,1.81))$ with the square error $=0.002798$ which can be seen in Fig. 4 .

\subsubsection{Patients' Service Distribution by Doctor2}

Service distribution of patients in case of doctor 1 came out to be triangular (TRIA $(3,9.13,14))$ with the square error $=0.002798$ which can be seen in Fig. 5 .

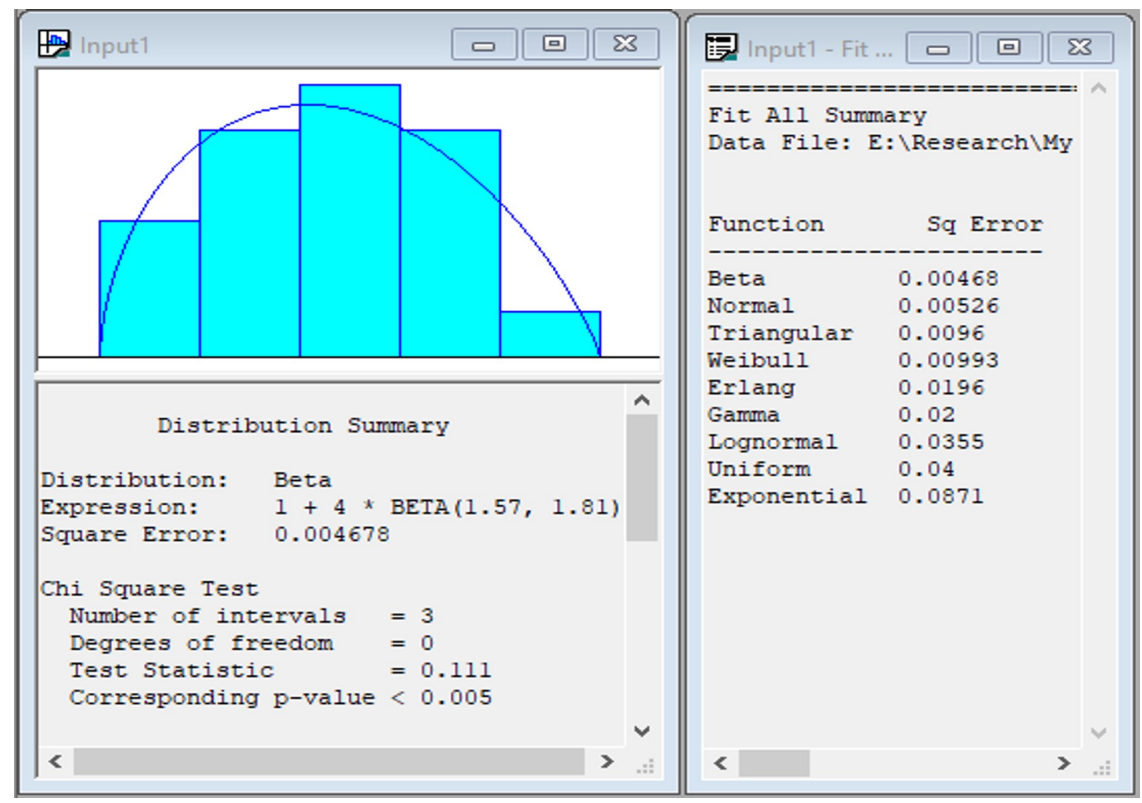

FIG. 4. DISTRIBUTION OF SERVED PATIENTS BY DOCTORI

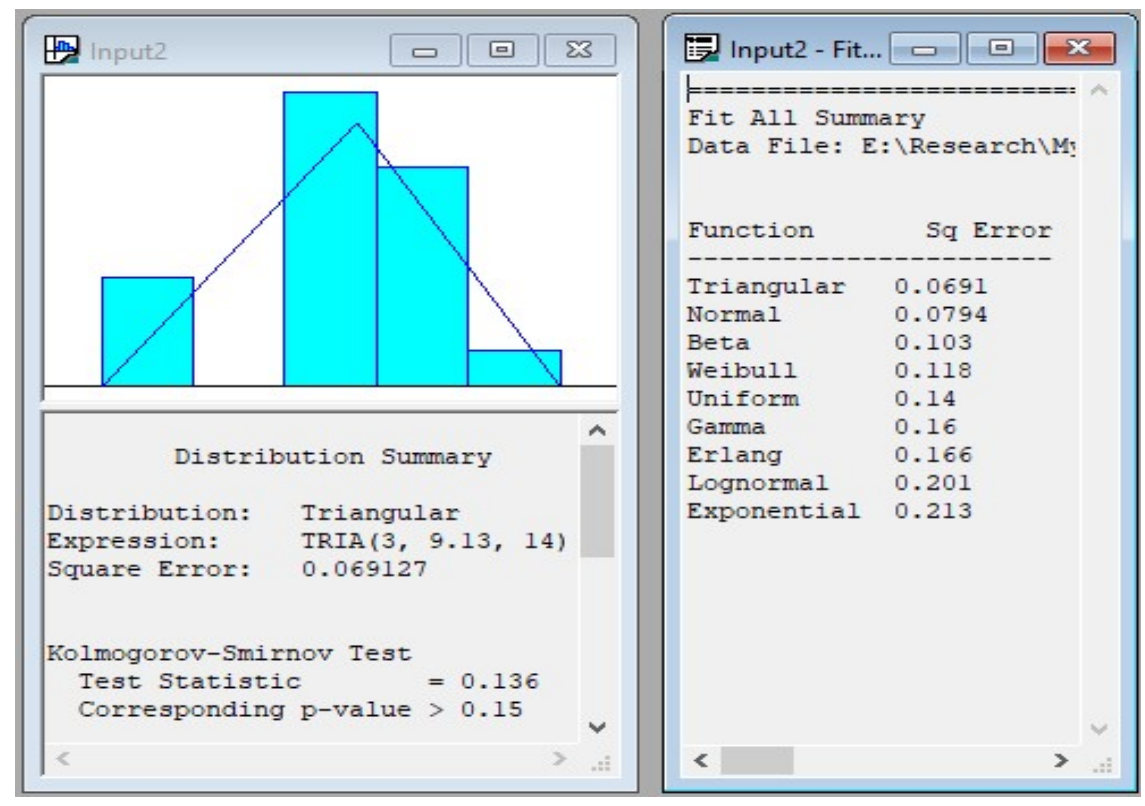

FIG. 5. DISTRIBUTION OF SERVED PATIENTS BY DOCTOR2 


\subsubsection{Patients' Service Distribution by Doctor3}

Service distribution of patients in case of doctor 3 came out to be normal distribution (NORM $(12.2,1.66))$ with the square error $=0.002798$ which can be seen in Fig. 6 .

\subsubsection{Patients' Service Distribution by Doctor4}

Service distribution of patients in case of doctor4 came out to be uniform distribution (UNIF $(3.29,10.9))$ with the square error $=0.002798$ which can be seen in Fig. 7 .

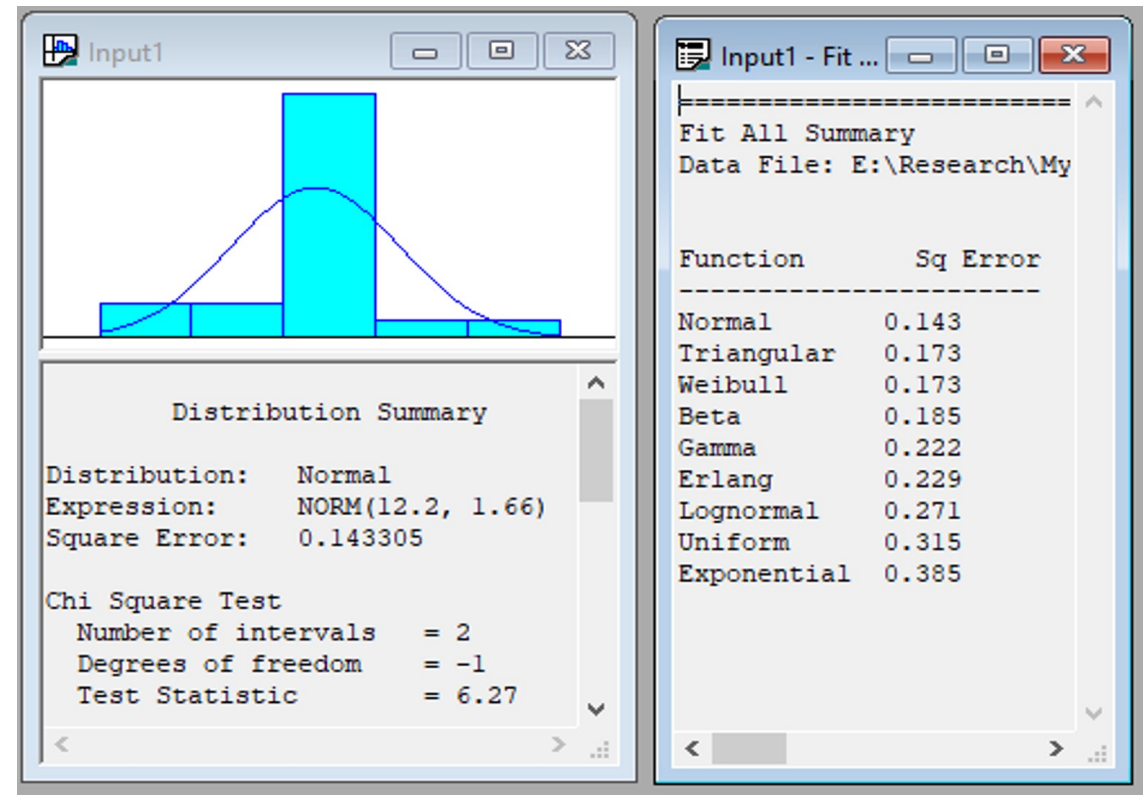

FIG. 6. DISTRIBUTION OF SERVED PATIENTS BY DOCTOR3

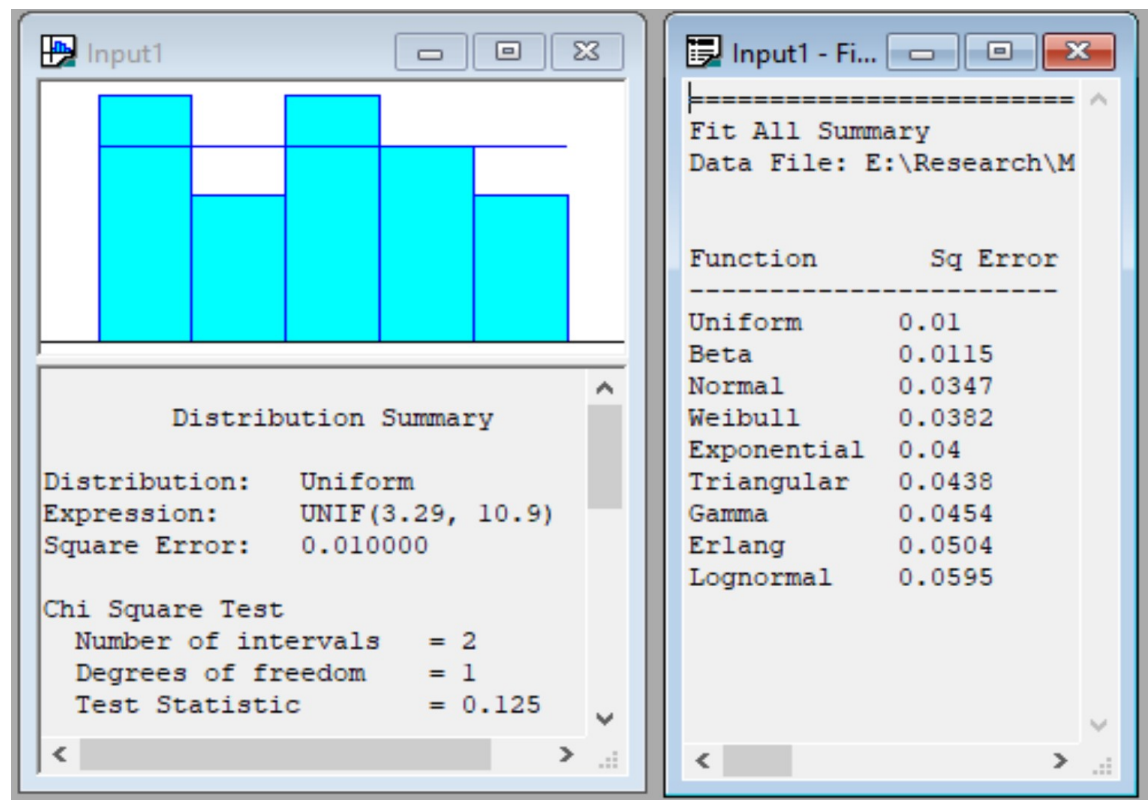

FIG. 7. DISTRIBUTION OF SERVED PATIENTS BY DOCTOR4 


\subsubsection{Patients' Service Distribution by Doctor5}

Service distribution of patients in case of doctor 5 came out to be triangular distribution (TRIA $(7.18,11,13.6)$ ) with the square error $=0.002798$ which can be seen in Fig. 8 .

\subsubsection{Patients' Service Distribution by Doctor6}

Service distribution of patients in case of doctor6 came out to be beta distribution $(11+7 x B e t a(1.45,1.47))$ with the square error $=0.002798$ which can be seen in Fig. 9.

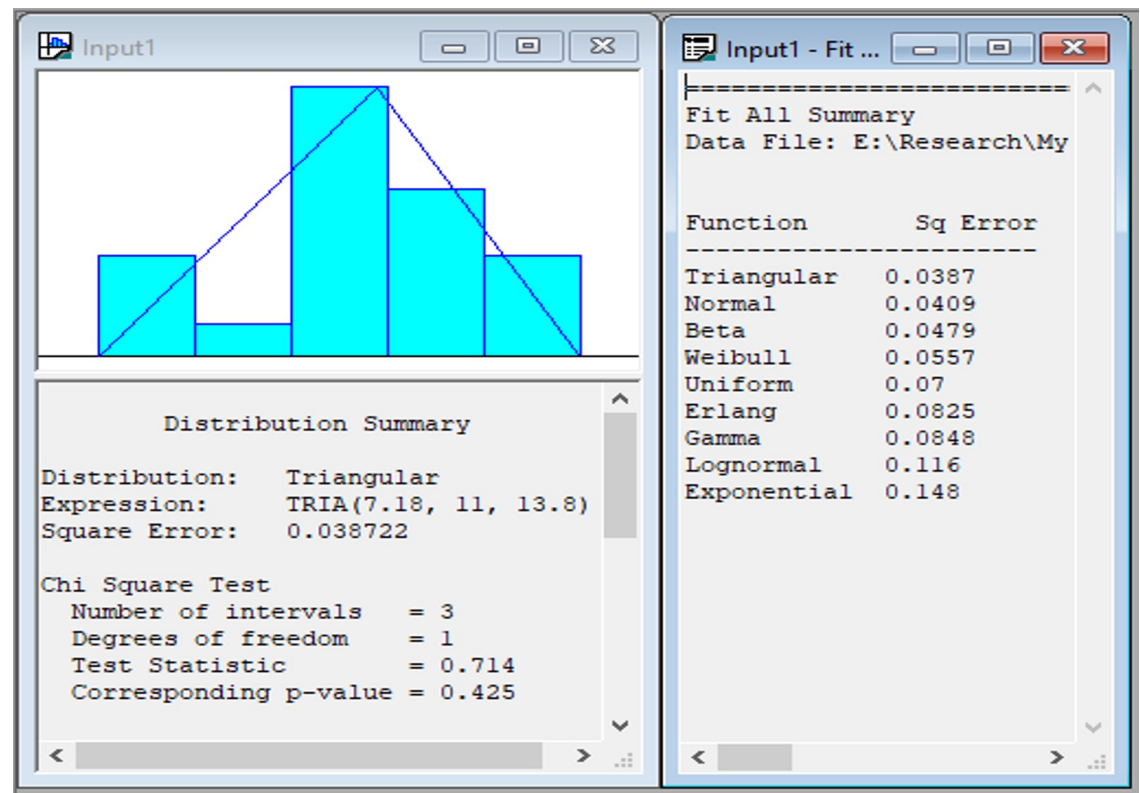

FIG. 8. DISTRIBUTION OF SERVED PATIENTS BY DOCTOR5

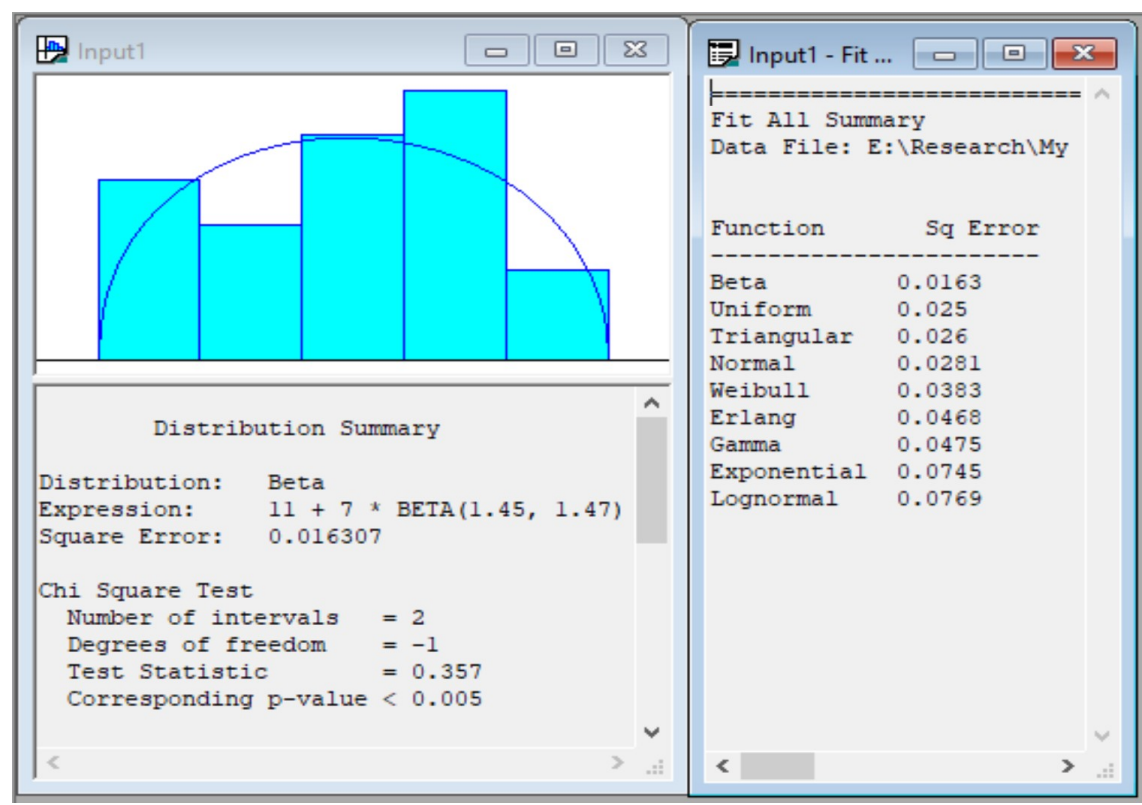

FIG. 9. DISTRIBUTION OF SERVED PATIENTS BY DOCTOR6 


\subsection{Modelling of the Queuing System of OPD}

In the development of queuing system model, patients were considered as entities, OPD was considered as system, receptionist, nurses and doctors were considered as resources.

\subsubsection{Simulation of Model for the OPD}

Queuing system of the OPD was modelled which can be seen in Fig. 10. In creating module (Patient Arrival) patients were created in the system. As figured out from the collected data that arrival distribution of patients at the OPD was poison distribution (POIS (19.8)). As discussed earlier, there were six doctors and the patients were coming for the specific doctors; all the arriving patients were identified with the help of assign module (DISC $(0.37,1$, $0.53,2,0.64,3,0.79,4,0.88,5,1,6)$ ). Furthermore, assign module was used to note the entrance time $($ MyArrivalTime $=\mathrm{TNOW}())$ of the arriving patients. For the service of patients at the reception, process module was used and the service distribution of patients at the reception came out to be triangular distribution (TRIA $(1.8,3.19,3.81))$ as shown in the Fig. 2 . When the patients got free of the reception, time spent by them at the reception was recorded (TNOW-MyArrivalTime) by the use of record module (Record Reception Time).

Similarly, before triage the time of patients was noted by the use of assign module. Service distribution of patients by the nurse was found to be normal (Norm $(2.14,0.442)$ ) as shown in the Fig. 3. Triage time of patients was recorded thereafter by the use of record module (Triage Time) as shown in the Fig. 10.

\subsubsection{Sub Model}

Since the patients were coming for the specific doctors that's why it was necessary to send them to the doctor of their interest. Sub model (Fig. 11) was initiated to model this mechanism of queuing system. Decide module (Nway by chance) was used for sending the patients to the specific doctors. Percentage of patients was calculated for each of the doctor $($ Doctor $1=37 \%$, Doctor $2=16 \%$, Doctor 3 $=11 \%$, Doctor $4=15 \%$, Doctor $5=9 \%$, Doctor $6=12 \%$ ).

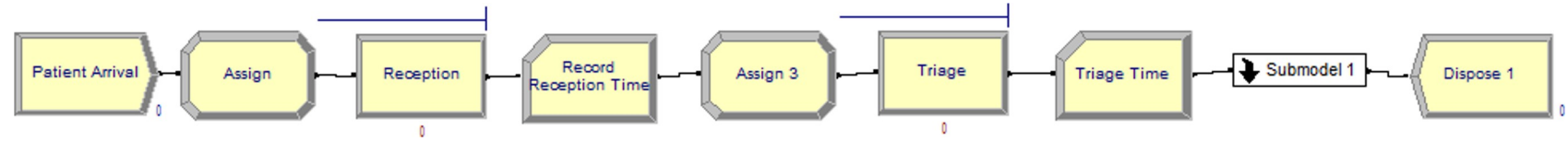

FIG. 10. MODEL OF THE QUEUING SYSTEM OF OPD

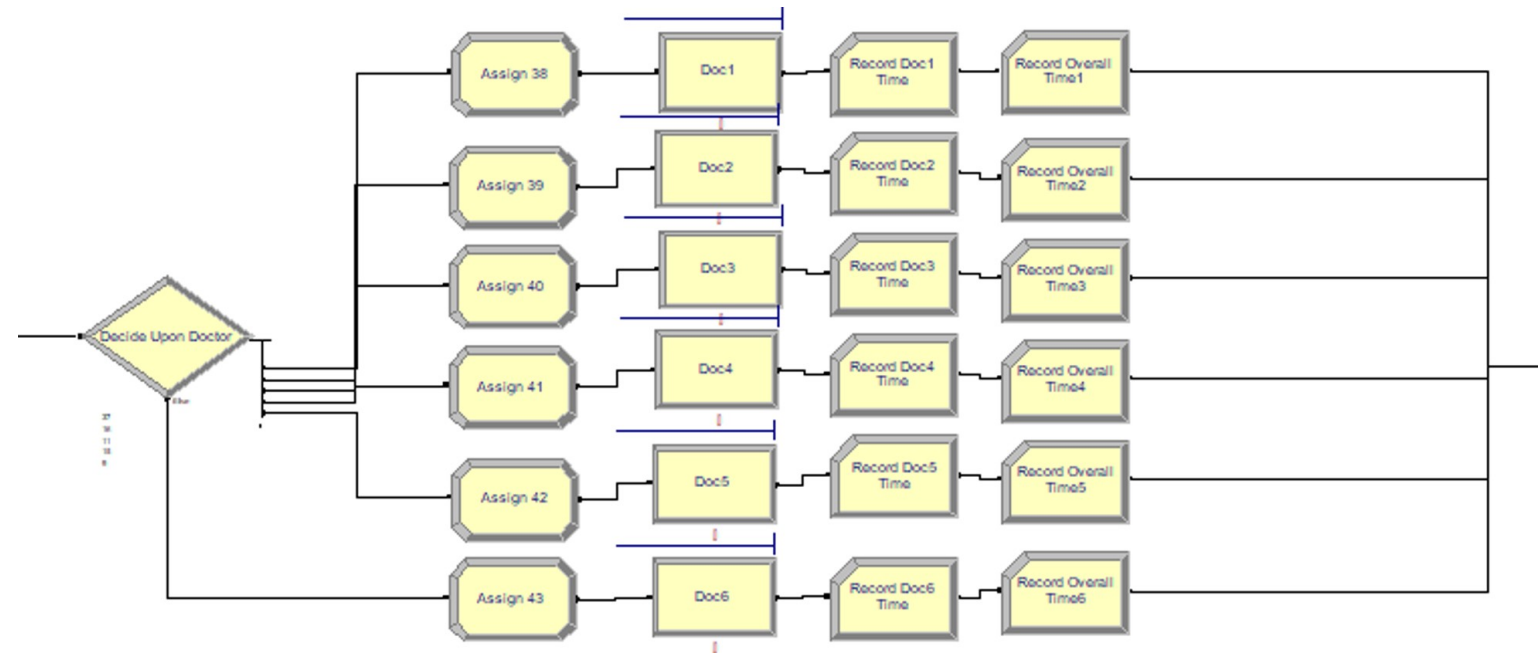

FIG. 11. SUB MODEL DEVELOPED FOR THE REPRESENTATION OF SERVICE MECHANISM OF PATIENTS BY THE DOCTOR AT THE OPD

Mehran University Research Journal of Engineering \& Technology, Volume 39, No. 1, January, 2020 [p-ISSN: 0254-7821, e-ISSN: 2413-7219] 
After deciding upon the patients to be sent to the specific doctor, the time of patients was noted by using the assign modules as shown in Fig. 11. Service distribution of patients by the doctors as collected from the OPD were: 'Doctor1: $1+4$ x Beta $(1.57,1.81)$ ', 'Doctor2: TRIA $(3,9.13,14)$ ', 'Doctor3: NORM (12.2, 1.66)', 'Doctor4: UNIF (3.29, 10.9)', 'Doctor5: TRIA (7.18, 11, 13.6)', 'Doctor6: 11+7x BETA $(1.45,1.47)$ '. When the patients got free from the doctor, their time was recorded by using record module (Record Doc1 Time) and in last, total system time of patients was recorded by using the record module. Since the time of doctors to serve the patients was different that is why the total system time of patients coming for different doctors was independently different.

\subsubsection{Replication Parameters}

It is required to set replication parameters as given in Table 2. The model was simulated for half year. OPD time was set to 4 hours and the unit of time in output was set to be in minutes.

\subsubsection{Results of Existing Queuing System}

Results which were obtained after simulating the model are presented in the below given headings.

\subsubsection{Number of patients Served by Each Doctor}

In the duration of 4 hours, 71 patients were served by the doctor 1 and it was the maximum number of patients and on the contrary 17 patients were served by the doctor 5 as shown in Table 3 . The number of patients served by each doctor depended on the service time of patients and the minimum service time was doctor 1 .

\subsubsection{Awaiting Patients in the Waiting Line}

In the queuing system of OPD, number of queues was eight. The number of awaiting patients in the various queues is presented in Table 4. It can be seen in the table that the maximum number of patients (i.e. 80) was awaiting at the reception. Average number of awaiting patients $(16.75)$ at the reception is also greater than all the averages.

TABLE 2. REPLICATION PARAMETERS SET FOR THE SIMULATION OF MODEL

\begin{tabular}{|c|c|c|}
\hline Replication Time & Durationof OPD/Day & BaselineTime \\
\hline 182 Days & 4 Hours & Minutes \\
\hline
\end{tabular}

TABLE 3. PATIENTS SERVED/HR AND PER DAY BY THE DOCTORS SPECIFICALLY

\begin{tabular}{|c|c|c|}
\hline Doctor & Number of Served Patients/Hour & Total Served Patients/Day \\
\hline Doctor 1 & 18 & 31 \\
\hline Doctor 2 & 8 & 21 \\
\hline Doctor 3 & 5 & 28 \\
\hline Doctor 4 & 7 & 17 \\
\hline Doctor 5 & 4 & 22 \\
\hline Doctor 6 & 6 & 190 \\
\hline Total & 48 & 22 \\
\hline
\end{tabular}

Mehran University Research Journal of Engineering \& Technology, Volume 39, No. 1, January, 2020 [p-ISSN: 0254-7821, e-ISSN: 2413-7219] 


\subsubsection{Waiting Time of Patients in the Queues}

Waiting time of patients in the various queues is presented in Table 5. On an average, the waiting time patients in different queues is quite less but in the queue of reception it was simulated to be 50.69 minutes. Maximum time of patients in the reception queue was 233 minutes. Secondly, the waiting time of patients in the queue of doctor 6 was 69.840 minutes; this time was more because of more service time (22.368 minutes (Table $8)$ ) of doctor6. Furthermore, waiting time of patients in the remaining queues was comparatively lesser as shown in Table 5 .

\subsubsection{Instantaneous Utilization of Resources}

In Table 6 instantaneous utilization of the available resources is presented. The maximum utilization was of the receptionist $(96.9 \%)$. Secondly, maximum utilization of the resource was of the doctor6 (55.8\%). However, the instantaneous utilization of other resources was comparatively less in the comparison of receptionist and doctor6.

TABLE 4. QUANTITY OF AWAITING PATIENTS IN THE WAITING LINE

\begin{tabular}{|c|c|c|c|}
\hline & Average Number & Minimum & Maximum \\
\hline Quantity of awaiting patients in queue of Doctor1 & 0.027 & 0 & 2 \\
\hline Number of awaiting patients in queue of Doctor2 & 0.163 & 0 & 6 \\
\hline Number of awaiting patients in queue of Doctor3 & 0.132 & 0 & 3 \\
\hline Number of awaiting patients in queue of Doctor4 & 0.070 & 0 & 3 \\
\hline Number of awaiting patients in queue of Doctor5 & 0.049 & 0 & 5 \\
\hline Number of awaiting patients in queue of Doctor6 & 0.304 & 0 & 80 \\
\hline Number of awaiting patients in reception queue & 16.75 & 0 & 0 \\
\hline Number of awaiting patients in triage queue & 0.000 & 0 & 5 \\
\hline
\end{tabular}

TABLE 5. PATIENTS WAITING TIME IN DIFFERENT WAITING LINES

\begin{tabular}{|c|c|c|c|}
\hline & Average Number & Minimum & Maximum \\
\hline Patients` waiting time in Doctor1`s queue & 0.218 & 0.00 & 7.0753 \\
\hline Patients` waiting time in Doctor2`s queue & 3.082 & 0.00 & 49.867 \\
\hline Patients` waiting time in Doctor3`s queue & 3.593 & 0.00 & 22.317 \\
\hline Patients`waiting time in Doctor4`s queue & 1.433 & 0.00 & 19.489 \\
\hline Patients`waiting time in Doctor5`s queue & 1.673 & 0.00 & 69.840 \\
\hline Patients`waiting time in Doctor6`s queue & 7.89 & 0.00 & 233.00 \\
\hline Patients`waiting time at reception queue & 50.69 & 0.00 & 0 \\
\hline Patients`waiting time in triage queue & 0 & 0 & 0 \\
\hline
\end{tabular}




\subsubsection{Recorded Time of Patients}

In Table 7 the recorded service time of doctors to serve the patients is presented. On the same time, total system time of patients coming to six different doctors was recorded separately as shown in Table 7 .

\subsection{Scenario Analysis}

Analysis was conducted in four scenarios; in each scenario the working time of resources was increased by one hour. Scenario analysis was conducted because of the existence of two queues. First was the queue of

TABLE 6. RESOURCES‘ INSTANTANEOUS UTILIZATION AT THE OPD

\begin{tabular}{|c|c|c|c|}
\hline Resource & Average Instantaneous Utilization & Minimum & Maximum \\
\hline Doctor1 & 0.3502 & 0 & 1 \\
\hline Doctor2 & 0.4646 & 0 & 1 \\
\hline Doctor3 & 0.4468 & 0 & 1 \\
\hline Doctor4 & 0.3486 & 0 & 1 \\
\hline Doctor5 & 0.3185 & 0 & 1 \\
\hline Doctor6 & 0.5580 & 0 & 1 \\
\hline Nurse & 0.3542 & 0 & 1 \\
\hline Reception & 0.9693 & 0 & 1 \\
\hline
\end{tabular}

TABLE 7. PATIENTS‘ SERVICE TIME AND THEIR TOTAL SYSTEM TIME

\begin{tabular}{|c|c|c|c|}
\hline & Average Number & Minimum & Maximum \\
\hline Service time of Doctor1 & 3.0576 & 1.0821 & 58.5460 \\
\hline Service time of Doctor2 & 11.871 & 3.0915 & 59.3339 \\
\hline Service time of Doctor3 & 15.767 & 7.1053 & 29.3528 \\
\hline Service time of Doctor4 & 8.5528 & 3.2907 & 29.7715 \\
\hline Service time of Doctor5 & 12.339 & 7.3612 & 87.4008 \\
\hline Service time of Doctor6 & 22.368 & 11.0240 & 239.47 \\
\hline Patients' total system time who came to for Doctor1 & 58.912 & 4.9865 & 242.94 \\
\hline Patients' total system time who came to for Doctor2 & 68.1742 & 8.5383 & 252.70 \\
\hline Patients' total system time who came to for Doctor3 & 71.3172 & 14.0216 & 238.77 \\
\hline Patients' total system time who came to for Doctor4 & 63.6784 & 8.1104 & 239.16 \\
\hline Patients' total system time who came to for Doctor5 & 68.9699 & 11.8030 & 250.58 \\
\hline Patients' total system time who came to for Doctor6 & 77.5622 & 15.6033 & 235.73 \\
\hline Waiting time of patients at Reception & 53.6307 & 1.8143 & 3.9295 \\
\hline Waiting time of patients at triage & 2.1449 & 0.1908 & \\
\hline
\end{tabular}

Mehran University Research Journal of Engineering \& Technology, Volume 39, No. 1, January, 2020 [p-ISSN: 0254-7821, e-ISSN: 2413-7219] 
patients which is in its way to see the doctor and another queue was virtual queue which was on hold to have an appointment. Therefore, second queue was required to be minimized so that more and more patients could be served.

\subsubsection{Replication Parameters}

Replication parameters were set before simulation. In scenario 1 , simulation time period was 0.5 year and the time of the OPD was 4 hours. Replication length was kept constant but the duration of OPD was changed by one hour as shown in Table 8.

\subsubsection{Patients Served by Specific Doctor in Different Scenarios}

Total number of served patients per day was calculated for each of the doctor across all scenarios. The number of served patients kept on increasing with the increasing working time of the OPD. The degree of increment can be seen in Table 9.

\subsubsection{Cost Analysis across all Scenarios}

Cost analysis was also conducted across all the scenarios. It included, service cost per day, total revenue of the hospital and total profit of the hospital as shown in Table 10

TABLE 8: REPLICATION PARAMETERS SET FOR SCENARIO ANALYSIS

\begin{tabular}{|c|c|c|c|}
\hline Scenario & Lengthof Replication (Days) & Durationof OPD/Day (Hours) & BaselineTime \\
\hline 1 & \multirow{4}{*}{182} & 4 & \multirow{4}{*}{ Minutes } \\
\hline 2 & & 5 & \\
\hline 3 & & 6 & \\
\hline 4 & & 7 & \\
\hline
\end{tabular}

TABLE 9. PATIENTS SERVED BY EACH DOCTOR PER HOUR AT THE OPD

\begin{tabular}{|c|c|c|c|c|c|c|c|}
\hline Scenario & $\begin{array}{c}\text { Patients Served by } \\
\text { Doctor1/Day }\end{array}$ & $\begin{array}{c}\text { Patients Served by } \\
\text { Doctor2/ Day }\end{array}$ & $\begin{array}{c}\text { Patients Served by } \\
\text { Doctor3/ Day }\end{array}$ & $\begin{array}{c}\text { Patients Served by } \\
\text { Doctor4/ Day }\end{array}$ & $\begin{array}{c}\text { Patients Served by } \\
\text { Doctor } 5 / \text { Day }\end{array}$ & $\begin{array}{c}\text { Patients Served by } \\
\text { Doctor6/Day }\end{array}$ & $\begin{array}{c}\text { Total Patients } \\
\text { Served/Day }\end{array}$ \\
\hline 1 & 72 & 32 & 20 & 28 & 16 & 24 & 192 \\
\hline 2 & 90 & 40 & 25 & 35 & 20 & 30 & 240 \\
\hline 3 & 108 & 48 & 30 & 42 & 24 & 36 & 288 \\
\hline 4 & 147 & 63 & 42 & 56 & 35 & 49 & 392 \\
\hline
\end{tabular}

TABLE 10. COST ANALYSIS OF SERVED PATIENTS ACROSS ALL THE SCENARIOS

\begin{tabular}{|c|c|c|c|c|}
\hline Scenario & Total Patients Served/Day & Service Cost/Day & Revenue of HospitalDay (Rs) & Total Profit of Hospital \\
\hline 1 & 190.3 & 14454.3 & 57090 \\
\hline 2 & 238.1 & 16667 & 71430 \\
\hline 3 & 286.5 & 20055 & 85950 \\
\hline 4 & 390.1 & 27307 & 117030 \\
\hline
\end{tabular}

Mehran University Research Journal of Engineering \& Technology, Volume 39, No. 1, January, 2020 [p-ISSN: 0254-7821, e-ISSN: 2413-7219] 


\subsubsection{Increased Percentage of Served Patients at the OPD}

In case of increasing sitting time of doctors at the OPD, the increased percentage of served patients was calculated which is presented in Fig. 12. In scenario, if the doctors' sitting time in the OPD is supposed to be 7 hours then, $105 \%$ would be the percentage of more patients who would be served at the OPD. Same case is with the revenue of the hospital it would certainly be increased in a way as number served patients. It can be seen in Fig. 12 that the revenue is increased up to $105 \%$ if the doctors are supposed to be seated in the OPD for 7 hours.

\subsubsection{Hospital's Cost on Each Patient}

The cost of the hospital on each of the arriving patient at the OPD was taken out. The amount which was charged by nurse per patient was Rs.51.07614; Amount charged by the receptionist was Rs.3.269838/- and the amount charged by the doctor per patients was Rs.70/-. Collectively, the total average amount charged by the resources was computed to Rs.124.34/- as shown in Table 11.

\subsubsection{Patients ${ }^{6}$ Waiting Time and cost in Different Scenarios}

During the simulation, some expression were formulated so that the total system time of patients could be recorded as shown in Table 6. Since, they wait in the system that's why cost is involved in it and that cost was termed as waiting cost/opportunity cost.

Waiting cost of patients across all the scenario was calculated and it was found to be minimum in the second scenario and was maximum in third scenario as shown in Fig. 13.

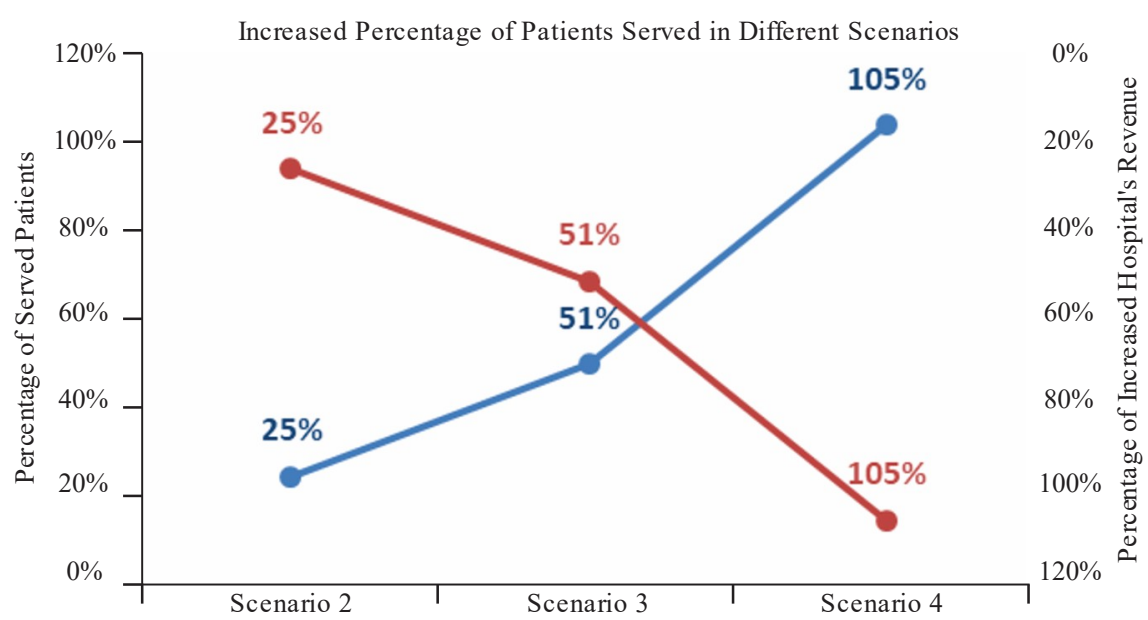

FIG. 12. PERCENTAGE OF SERVED PATIENTS WHEN THE DOCTORS' OPD TIME WOULD BE INCREASED

TABLE 11: AVERAGE SERVICE COST OF HOSPITAL SPENT ON EACH PATIENT

\begin{tabular}{|c|c|}
\hline Cost & Amount (Rs) \\
\hline Nurses' cost/patient & 51.1 \\
\hline Receptionist's cost/patient & 3.3 \\
\hline Doctor's cost/patient & 70 \\
\hline Total cost/patient & 124.34 \\
\hline
\end{tabular}

Mehran University Research Journal of Engineering \& Technology, Volume 39, No. 1, January, 2020 [p-ISSN: 0254-7821, e-ISSN: 2413-7219] 


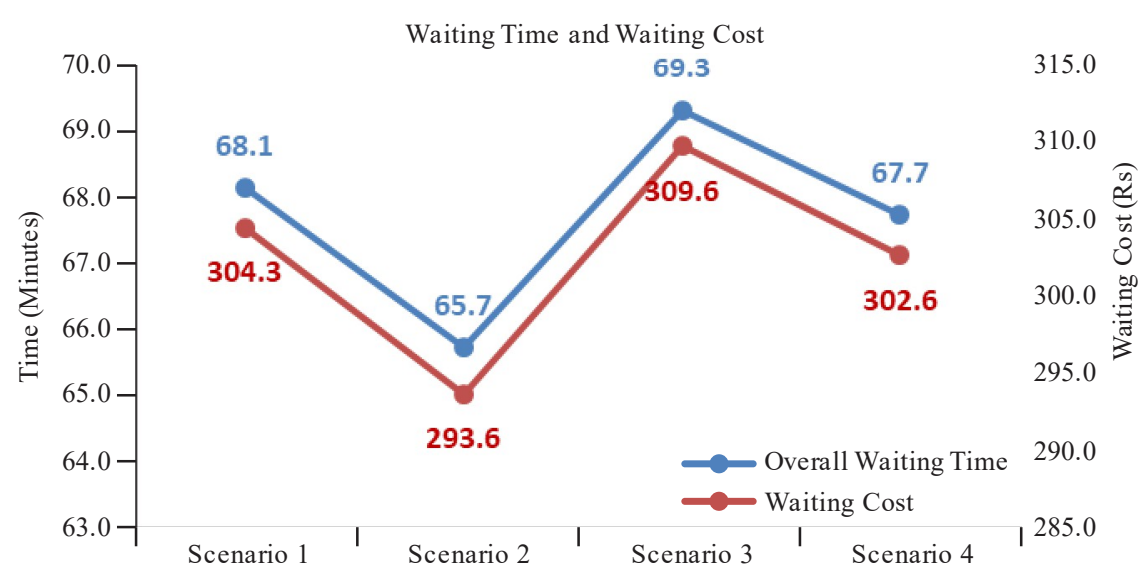

FIG. 13. PATIENTS`WAITING COST IN DIFFERENT SCENARIOS

\section{CONCLUSION}

It was not possible to increase the number of doctors at the OPD because the patients were coming for particular doctors at the OPD; since it was aimed to put the suggestion by which the maximum number of patients could be served, therefore, currently available doctors were suggested to sit for longer. If the doctors are supposed to sit for 7 hours in the OPD then 105\% more patients would be served as compared to the existing service rate of the OPD.

\section{FUTURE WORK}

In this research, total system time of patients at the OPD was considered for the waiting cost. Time spent by the patients at the pharmacy was not included in this study therefore, it should be considered in the future studies. On the same time patients also spent the time on their way to hospital and the way back to their homes. This time was not also considered for the calculation of waiting cost of patients.

(i) Instead of poison distribution, normal distribution can also be used for arrival of patients because both distributions are of the same square error. (ii) Tea breaks for the operational staff and occasional non-availability of the resources should be the consideration in future research.

(iii) Whole data should also be collected two to three times a year in order to produce the justified results.

\section{MANAGERIAL INSIGHTS}

This study helps the hospital administration to improve the healthcare performance. It was revealed during this study that a few numbers of patients may shift to other doctors if they will properly guide by hospital administration. These patients are usually come first time to OPD. By doing this, patients waiting time may reduce as they may be shifted to doctors with shorter queues.

\section{ACKNOWLEDGEMENT}

This research could not have been conducted without the generous contribution of co-authors and Mehran University of Engineering \& Technology, Jamshoro, Pakistan. Additionally, we thank the hospital administration for their good cooperation for permitting us to collect and providing the acquired data for research. 


\section{REFERENCES}

Iqbal, S., and Khan, N., "Effectiveness and Future Prospects of Telemedicine/Remote Health Care Management Applications in Pakistan", Mehran University Research Journal of Engineering \& Technology, Volume 36, No. 4, Jamshoro, Pakistan, October, 2017.

Mashhadi, S.F., Hamid, S., Roshan, R., and Fawad, A., "Healthcare in Pakistan- A Systems Perspective", Pakistan Armed Forces Medical Journal, No. 66, 2016.

[3] Seth, N., Yeboah, F.B., and Adiwokor, E., "Client Satisfaction with Service Delivery in the Health Sector: The Case of Agogo Presbyterian Hospital", International Journal of Business Administration, Volume 6, No. 4, pp. 64, 2015.

[4] Kudra, K., and Njau, B., "Patients' Level of Satisfaction on Quality of Health Care at Mwananyamala Hospital in Dar Es Salaam, Tanzania”, BMC Health Services Research, Volume 14, No. 1, pp. 400, 2014.

Dudung, J., Manik, E., Febrinella, C., and Sidharta, I., "Empirical Study on Patient Satisfaction and Patient Loyalty on Public Hospital in Bandung, Indonesia”, International Journal of Applied Business and Economic Research, Volume 13, No. 6, pp. 4305-4326, 2015.

Liga, S., "Service Quality, Customer Value and Patient Satisfaction on Public Hospital in Bandung District, Indonesia", International Review of Management and Marketing, Volume 7, No. 2, pp. 187-92, 2017.

Kembe, M.M., Onah, E.S., and Iorkegh, S., "A Study of Waiting and Service Costs of a Multi-Server Queuing Model in a Specialist Hospital", International Journal of Scientific \& Technology Research, Volume 1, No. 8, pp. 19-23, 2012.

[8] Haghighinejad, H.A., Kharazmi, E., Hatam, N., Yousefi, S., Hesami, S.A., Danaei, M., and Askarian, M., "Using Queuing Theory and Simulation Modelling to Reduce Waiting Times in an Iranian Emergency Department", International Journal of Community Based Nursing and Midwifery, Volume 4, No. 1, pp. 11, 2016.
[9] Sajid, M., Ahsan, K., and Sarim, M., "M-Health Service for Train Passengers Using Mobile GPS System: An Archimate Service Layer Model”, Mehran University Research Journal of Engineering \& Technology, Volume 36, No. 1, pp. 21-32, Jamhsoro, Pakistan, 2017.

[10] Agyei, W., Christian, A-.D., and Frank, O., "Modeling and Analysis of Queuing Systems in Banks: A Case Study of Ghana Commercial Bank Ltd. Kumasi Main Branch”, Economic Analysis, Volume 1, No. 2, 2015.

[11] Mwangi, S.K., and Thomas, M.O., “An Empirical Analysis of Queuing Model and Queuing Behaviour in Relation to Customer Satisfaction at Jkuat Students Finance Office", American Journal of Theoretical and Applied Statistics, Volume 4, No. 4, pp. 233-46, 2015.

[12] Agarwal, R., and Singh, B.K., "An Analytical Study of Queues in Medical Sector", OPSEARCH, Volume 55, No. 2,pp. 268-87, 2018.

[13] Wang, T., Alain, G., Aissam, B. and Beatrix, B., "Modelling and Simulation of Emergency Services with Aris and Arena: Case Study: The Emergency Department of Saint Joseph and Saint Luc Hospital",Production Planning and Control, Volume 20, No. 6, pp. 484-95, 2009.

[14] Uriarte, A.G., Zúñiga, E.R., Urenda, M., andNg, A.H.C., "System Design and Improvement of an Emergency Department Using Simulation-Based Multi-Objective Optimization", Journal of Physics: Conference Series, 2015.

[15] Tandon, A., Christopher, J.L., Murray, J., Lauer, A., and David, B.E., "Measuring Overall Health System Performance for 191 Countries", World Health Organization, Geneva, 2000.

[16] Gunal, M.M., “A Guide for Building Hospital Simulation Models", Health Systems, Volume 1, No. 1, pp. 17-25, 2017. 
[17] Dawei, R., Liu, Z., and Zhao, S., "Process Analysis of Hospital Outpatient Service Based on Arena”, IEEE $16^{\text {th }}$ International Conference on Industrial Engineering and Engineering Management, pp.1364-1367, 2009.

[18] Kittipittayakorn, C., and Kuo-Ching, Y., "Using the Integration of Discrete Event and Agent-Based Simulation to Enhance Outpatient Service Quality in an Orthopedic Department", Journal of Healthcare Engineering, 2016.

[19] Lade, I.P., Chowriwar, S.A., and Sawaitul, P.B., "Simulation of Queuing Analysis in Hospital",International Journal of Mechanical Engineering and Robotics Research, Volume 2, No. 3, pp. 122-128, 2013.
[20] Nuñez-Perez, N., Ortíz-Barrios, M., McClean, S., SalasNavarro, K., Jimenez-Delgado, G., and Castillo-Zea, A., "Discrete-Event Simulation to Reduce Waiting Time in Accident and Emergency Departments: ACase Study in a District General Clinic",International Conference on Ubiquitous Computing and Ambient Intelligence, Cham, pp. 352-363, Springer, 2017.

[21] Mwafak S., Al-Nasra, M., Jadayil, W.A., Jaber, N., and Jadayil, S.A., "Evaluation of Provided Services at MRI Department in a Public Hospital Using Discrete Event Simulation Technique: A Case Study", Cogent Engineering, Volume 4, No. 1, pp. 1403539, 2017.

[22] Holmes, D.T., and Kevin, B., "Mathematical Modeling: Assumptions Affect Results", Clinical Chemistry, Volume 52, No. 8, pp. 1606-1608, 2006. 